\title{
Determinants of Demand for Physical Activity among Students in Krakow
}
Authors' contribution:
A) conception and design of the study
B) acquisition of data
C) analysis and interpretation of data
D) manuscript preparation
E) obtaining funding

\author{
Szczepan Kościółek \\ University of Economics, Kraków, Poland \\ University of Economics, Kraków, Poland
}

ABSTRACT

The low level of physical activity amongst Poles is not only a social problem, but also a big challenge for commercial organizations. The aim of the thesis was to determine indicating factors influencing the maximum price that students are prone to pay for physical activity. The research was based on the opinions of 398 respondents (students from Krakow's academies). A Chi-square test of independence was used to compare the distribution of the observed variables with their theoretical distribution.

The test results show that the maximum price that students are prone to pay for a single admission ticket and for a monthly pass for participating in physical activity is correlated with the price of complementary goods, participation in free and paid kinesthetic forms of recreation, and their main subject of study. In the case of the decision to purchase monthly passes (as opposed to a ticket for single admission), the student's income and motivation to exercise are also important. On the other hand, declarative price is not influenced by the gender and former sports activity of interviewees.

KEYWORDS physical activity, physical recreation, pricing, consumer behavior

\section{Introduction}

The level of sporting activity among Polish people is significantly lower that in many other European countries (European Commission 2014). However, participation in sports activities generates important health, social, and even economic benefits. The most obvious benefit of physical activity is that it improves health (Cavill et al. 2006, p. 6). On the one hand, sports can reduce the risk of ailments such as heart attacks, obesity, diabetes, lung cancer, or depression. On the other hand, a stint of exercise can induce positive changes in the psychophysical condition and the general development of muscle tissue. There are also important economic and social consequences of participating in sports activities (Gledhill 2007, p. 262). In the social dimension, one can determine the benefits associated with improving the skills of cooperation, leveling alienation, and becoming more confident. The economic impact of sporting activities is that they reduce the potential costs associated with the treatment of diseases, increase growth in the job market, support local entrepreneurship, prevent social exclusion, and improve labor productivity. 
Given the important potential benefits of sport and the low activity of Polish people in this area, the need to understand the mechanisms of participation in sports characterizing various socio-economic and age groups of Poles becomes evident. The aim of this work is to define the determinants of physical activities and the maximum price Polish students are willing to pay to engage in these activities.

The selection of students as the study group is motivated by two reasons. First, supporting pro-sports attitudes and habits among young people may be considered a long-term investment from the point of view of public policy. Moreover, most commercial sports offers target young people. Hence, the results of this study can be useful for public authorities (government, universities) aiming to increase the participation of young people in sports and for commercial institutions seeking to optimize the elements of the marketing mix for different market segments.

The paper is structured as follows. First, a literature review in search of variables influencing physical activity is presented. Second, the hypotheses and research methodology are defined. The third section presents and discusses the results of the research concerning determinants of the maximum price students are willing to pay for physical activity. The final sections conclude the paper.

\section{Determinants of physical activity}

C. Breuer, K. Hallmann, and P. Wicker (2010, pp. 61-70) divide the factors affecting the demand for physical activity into demographic and economic variables, among which gender and income are the most important. Nevertheless, according to F. Lera-Lopez and M. Rapun-Garate (2011, pp. 66-89), the demand for physical activity is limited mainly by economic, sociological, and psychological variables: in addition to age and gender, having a job and enough free time are the main drivers of sports participation. Yet the weight of these variables differs by country. In general, demand for sports services in the European Union is dependent on age, number of children, family relations, education (the higher the better), and place of residence (the bigger the city, the higher the sport activity among residents; Hovemann et al. 2009, pp. 51-59).

Price

The level of expenditure on sporting activity is determined by the costs associated with the activity, income, and prices of substitute goods, and the combination of these factors depends on the individual preferences of the individual (Taylor et al. 2002, pp. 50-54). The price of a sports service does not include the cost of entry into a sports facility, but also transport costs, the price of substitute goods, the cost of suitable equipment, and time spent on the activity. A decline in demand for physical activity is especially noticeable when a hitherto free sport service becomes a paid one (Kirby et al. 2013, pp. 954-969).

\section{Income}

F. Lera-Lopez and M. Rapun-Garate (2005, pp. 167-186) consider the notion that despite the statistical significance of the relationship between income and expenses associated with physical activity, this parameter does not play a major role in shaping the demand for sport. Yet other studies do not support this conclusion, and instead show a positive correlation between earnings and expenses related to physical activity (e.g., Candemir \& Zallugoglu 2012, p. 29-39; Humphreys \& Ruseski 2011, p. 1-38). Using data from the Central Statistical Office, P. Strawinski (2011, pp. 55-76) proved that economic and demographic factors affect access to sporting activity in Poland, and income level is a major economic factor determining the demand for physical activity.

\section{Gender}

Women, especially women with children, spend less money than men on sporting activities (Klein 2009, p. 1-32). Moreover, they also spend less time on physical activity during the day (Belcher et al. 2010, pp. 2211-2221).

\section{Individual experience}


Within the context of family patterns, sports have a positive impact on children's physical activity (Bandura 1994, pp. 71-81). The family can have a positive influence on the attitudes of children towards sport through verbal support for their activities (Stuart et al. 2015) and education (as the demand for sports rises with education levels; Klein 2009, pp. 1-32). Physical activity is also affected by the availability of sports facilities (Dagkas \& Stathi 2007; pp. 369-385), even if R. G. Prins (2011, pp. 1228-1234) undermines the impact of the availability of sports facilities on the physical activity of youth.

The willingness to pay for physical activity is especially high among members of sports clubs and those who are more frequently active (Herens et al. 2015). The greater the frequency of physical activity, the higher the price the person engaged is willing to pay for it. Past participation in sports has no influence on current physical activity, as, according to S. G. Trost et al. (2002, pp. 1996-2001), people can completely cease activity practically from day to day.

\section{Motivation}

The motivation to participate in sports is based on the enjoyment of physical activity, health issues, and the desire to improve one's appearance and social and family environment (Allender et al. 2006, pp. 826-835). For youth, sports play a social role: they allow for the building of positive relationships amongst peers (Webber \& Mearman 2008, pp. 1183-1190). Still, people who point to physical activity as a form of relaxation are prone to exercise more frequently than those who exercise mainly for improved health and appearance (Anokye et al. 2012, pp. 227-287).

\section{Methodology}

The aim of the thesis was to define the factors that determine physical activity among students in Krakow. The question of whether variables pointed to in foregoing studies influence the maximum price of physical activity that students of Krakow academies are prone to pay for was researched.

The declared price concerned two decisions: buying a single admission ticket and buying a monthly pass granting access to facilities (gym and swimming pool) offering space for recreation.

Some of the factors indicated in the literature, such as age and education, were omitted due to the fact that the research group was relatively homogeneous in this regard. The case of access to sports facilities was also omitted because all respondents currently live in the same city (Krakow). Based on the results of the studies presented in the previous chapter, we can hypothesize that:

- H1: Male students are able to spend more on physical activity than female students.

- H2: Higher nominal income increases the maximum price that students are able to pay for physical activity.

- H3: The increase of prices of complimentary goods negatively influences the price that students are prone to pay for the right service.

- H4: Students who participate in free sports activities are willing to spend less on paid activities than others, and students who benefit from paid forms of activity are willing to accept a higher price than the rest.

- H5: Students who engage in physical activity for pleasure are able to spend more on paid activity than students guided by other motives (i.e., health issues, weight loss, etc.).

- H6: Students whose families practice sports are able to pay more for physical activity than others. Students who have had a pattern of sports participation in their family are able to pay more than others for physical activity.

- H7: Studying a sport profile subject (and having friends who are physically active) has a positive effect on the maximum price that students are willing to pay for this kind of entertainment.

- H8: Students who have previously trained in clubs do not generate a greater demand for paid physical activity than others. 
The study had two stages. The first one included conducting an anonymous survey. The research was conducted on October 1-10, 2015 on a random sample of 398 university students in Krakow using a direct interview based on a paper questionnaire at Jagiellonian University, AGH University of Science and Technology, the Pedagogical University, and the Academy of Physical Education in Krakow. The study was accompanied by an electronic version of the same survey dedicated to students from other universities. The questionnaire consisted of 24 closed or semi-open questions. Women were the dominant group, accounting for $65 \%$ of all respondents. A detailed division of respondents on the grounds of academic membership and sex is presented in Table 1.

Table 1. Academic membership by gender

\begin{tabular}{lccccc}
\hline \multicolumn{1}{c}{ University } & Number tested & Men & \% & Women & \% \\
\hline Jagiellonian University & 139 & 32 & 23 & 107 & 41 \\
AGH University of Science and Technology & 133 & 63 & 46 & 70 & 27 \\
University of Physical Education & 48 & 15 & 11 & 33 & 13 \\
Pedagogical University & 40 & 6 & 5 & 33 & 13 \\
Krakow University of Economics & 26 & 13 & 9 & 13 & 5 \\
Other* & 13 & 8 & 6 & 5 & 2 \\
\hline Total & 398 & 138 & 35 & 260 & 65 \\
\hline
\end{tabular}

Source: own study

According to the formula:

$$
n=\frac{N}{1+\frac{4(N-1) d^{2}}{u_{\alpha}^{2}}}
$$

where $\mathbf{N}$ is the estimated strength of the population, $\mathbf{u}_{\boldsymbol{\alpha}}$ is the standard normal distribution $\mathbf{N}(0 ; 1)$, and $\mathbf{d}$ is a precision row of rate structure assessment (as a percentage), in the research of consumer behaviors of students from academies in Krakow (size of population: 210,000), the number of observations should amount to at least 383 to conclude at a trust level of $95 \%$. Thus, the size of the survey sample $(n=398)$ was selected in a proper manner and can be considered to be representative.

In the second stage of the research, the results of the survey were put into the Chi-square test of independence. The choice of this method was conditioned by the necessity to study the effect on the price of variables relating to, among other things, sex, motivation, previous experience, and current market behavior. First the test of compliance was carried out, and differences between the observed empirical data and theoretical data were checked.

In order to conduct the study with the Chi-square test, quantitative data, such as prices and incomes, were divided into three variables according to percentage values and position in the dataset. For each:

$$
\begin{aligned}
& -\quad x<33 \%-\text { assigned value " } 1 \text { " (low) } \\
& -\quad x \leq 33 \% \text { and } x<66 \%-\text { assigned value " } 2 " \text { (middle) } \\
& -\quad x \geq 66 \%-\text { assigned value " } 3 \text { " (high) }
\end{aligned}
$$

\section{Results and discussion}

The specificity of the student population is its relatively low net income in this segment of the market: on average, approximately 1,149 PLN (including support from parents, scholarships, work, etc.), while the average in the national economy in the first half of 2015 amounted to a little more than 2,800 PLN net (Central Statistical Office of Poland 2015). In the study group, 64\% of respondents participate in payable forms of physical activity at least once a week on average, and $77 \%$ do sports free of charge (including fitness programs available for free on the Internet, and running). The respondents use various forms of physical activity 1.95 times per week on average. Those who do not do this usually suggest laziness and a lack of interest in sports as a cause, and more rarely claim that injuries eliminate them from this form of entertainment. 
Chi-square independence tests allow for an indication of which of the researched variables are statistically essential and influence the maximum price that students are prone to pay for a single admission ticket and monthly pass to facilities for physical activities. The findings (Table 2) indicated that the variables that influence the maximum price that students are able to pay for access to physical activity facilities requiring payment are price of complementary goods needed to participate in the sport, association with the sports club, use of free forms of physical recreation, family sports traditions, and, in the case of the price of monthly access, monthly income.

Table 2. Research of Chi-square test of independence

\begin{tabular}{lccccc}
\hline \multicolumn{1}{c}{ Variable } & $\begin{array}{c}\text { Degrees of } \\
\text { freedom }\end{array}$ & \multicolumn{2}{c}{ Single ticket } & \multicolumn{2}{c}{ Monthly pass } \\
& chi-square & p-value & chi-square & p-value \\
\hline Price of complementary goods & 4 & $24.32^{* *}$ & 0.004 & $34.18^{* * *}$ & 0.000 \\
Sports field of study & 2 & $13.29^{* *}$ & 0.004 & $13.75^{* *}$ & 0.003 \\
Use of paid forms of training & 2 & $12.28^{* *}$ & 0.006 & $29.65^{* * *}$ & 0.000 \\
Use of free forms of training & 2 & $10.78^{*}$ & 0.013 & $19.34^{* * *}$ & 0.000 \\
Sports club membership & 2 & $8.52^{*}$ & 0.036 & 6.42 & 0.093 \\
Training motivation & 4 & 8.33 & 0.215 & $23.78^{* *}$ & 0.001 \\
Monthly income & 4 & 5.11 & 0.276 & $20.97 *$ & 0.013 \\
Gender & 2 & 3.70 & 0.157 & 1.40 & 0.705 \\
Sports tradition in family & 4 & 5.39 & 0.495 & 3.90 & 0.691 \\
\hline
\end{tabular}

Significance at the level: $* \mathrm{p}<0.05 ; * * \mathrm{p}<0.01 ; * * * \mathrm{p}<0.001$

Source: own study

Despite the fact that the male respondents were more often interested in playing sports than the female respondents (according to the survey of active people, $79 \%$ of the men were active, while $56 \%$ of the women were active), sex is not a statistically significant variable (significance level $\alpha=0.05$ ) influencing willingness to pay for sports services. This is the basis for rejecting research hypothesis H1. This is contrary to the results of the research of Klein (2009, pp. 1-32) and Lera-Lopez and Rapun-Garate (2005), whose studies indicate that men are willing to spend more on physical activity than women.

Likewise, students who had a connection with sports environments during childhood (according to family sports traditions) are not willing to pay higher prices than the other students for a single admission ticket and monthly pass allowing access to physical recreation. Regardless, Bandura (1994, pp. 71-81) indicates that alongside familial surroundings, the pressure of friends is a major stimulus motivating people to engage in sport. This does not confirm the $\mathbf{H 6}$ research hypothesis.

Table 3 shows the effect of explanatory variables on the maximum price that students are willing to pay for a single admission ticket and monthly pass allowing access to facilities for physical recreation.

Monthly incomes are not statistically significant only in case of the smaller expense (single ticket). The growing price of monthly passes led to a decline in the tendency to purchase them among people earning the least (when the price is low, the observed values exceed the theoretical by $34 \%$; for average prices, $0 \%$; for higher prices, $66 \%$ ). At the same time, when this occurs, the participation of people with higher incomes grows. Thus, the $\mathbf{H} \mathbf{2}$ hypothesis must be regarded as having been satisfied, just as the research paper of L. Farrell and M. A. Shields (2002, pp. 335-348) shows that the demand for paid physical recreation largely depends on income; similar conclusions are presented by P. Strawinski (2011, pp. 55-76) for the Polish market and are confirmed in this market segment. 
Table 3. The impact of the explanatory variables on the maximum price that students are willing to pay for a single admission ticket and monthly pass to sports facilities

\begin{tabular}{|c|c|c|c|c|c|c|}
\hline \multirow{3}{*}{ Variable } & \multicolumn{6}{|c|}{ Maximum declarative price } \\
\hline & \multicolumn{3}{|c|}{ Monthly pass } & \multicolumn{3}{|c|}{ Single ticket } \\
\hline & Low & Medium & High & Low & Medium & High \\
\hline \multicolumn{7}{|c|}{ Price of complementary goods } \\
\hline Low & $45 \%$ & $-13 \%$ & $-50 \%$ & $28 \%$ & $-12 \%$ & $-56 \%$ \\
\hline Medium & $-17 \%$ & $11 \%$ & $2 \%$ & $-20 \%$ & $6 \%$ & $47 \%$ \\
\hline High & $-36 \%$ & $8 \%$ & $48 \%$ & $-17 \%$ & $10 \%$ & $26 \%$ \\
\hline \multicolumn{7}{|c|}{ Free training } \\
\hline No & $20 \%$ & $2 \%$ & $-44 \%$ & $26 \%$ & $-5 \%$ & $-65 \%$ \\
\hline Yes & $37 \%$ & $-1 \%$ & $13 \%$ & $-2 \%$ & $2 \%$ & $20 \%$ \\
\hline \multicolumn{7}{|c|}{ Motivation* } \\
\hline Lacking & $71 \%$ & $-18 \%$ & $-87 \%$ & - & - & - \\
\hline Short-term goals & $26 \%$ & $-18 \%$ & $1 \%$ & - & - & - \\
\hline Pleasure & $-21 \%$ & $10 \%$ & $14 \%$ & - & - & - \\
\hline \multicolumn{7}{|c|}{ Use of paid forms } \\
\hline No & $43 \%$ & $-8 \%$ & $-61 \%$ & $22 \%$ & $-10 \%$ & $-42 \%$ \\
\hline Yes & $-25 \%$ & $5 \%$ & $34 \%$ & $-12 \%$ & $6 \%$ & $24 \%$ \\
\hline \multicolumn{7}{|c|}{ Income* } \\
\hline Low & $34 \%$ & $0 \%$ & $-66 \%$ & - & - & - \\
\hline Medium & $3 \%$ & $2 \%$ & $-12 \%$ & - & - & - \\
\hline High & $-25 \%$ & $-2 \%$ & $55 \%$ & - & - & - \\
\hline \multicolumn{7}{|c|}{ Sports field of study } \\
\hline No & $4 \%$ & $1 \%$ & $-11 \%$ & $3 \%$ & $1 \%$ & $-12 \%$ \\
\hline Yes & $-47 \%$ & $-19 \%$ & $144 \%$ & $-40 \%$ & $-14 \%$ & $152 \%$ \\
\hline \multicolumn{7}{|c|}{ Sports club membership** } \\
\hline No & - & - & - & $10 \%$ & $-3 \%$ & $-10 \%$ \\
\hline Yes & - & - & - & $-28 \%$ & $9 \%$ & $29 \%$ \\
\hline
\end{tabular}

*The variables "motivation" and "income" are not statistically significant for the declared price for the single admission ticket at the level of $\mathrm{p}<0.05$.

**The variable "sports club membership" is not statistically significant for the declared price for the monthly pass at the level of $\mathrm{p}<0.05$.

Source: own study

Likewise, the willingness to pay for a physical activity is different in the case of the price of a monthly pass. In a study conducted on American campuses, the vast majority of students indicated the pleasure of sport as the main reason for their physical activity (Kilpatrick 2005, pp. 87-94). According to the results of the research conducted among students in Krakow, the character of the motivation as the fundamental element for paid physical activity has an impact on the potential demand associated with it. Those who derive pleasure from sport on a greater scale than persons whose physical activity is connected with immediate goals (related to improving posture and health issues) are able to pay a higher price for physical activity (their contribution exceeds the theoretical value by $5 \%$ for the ticket and $13 \%$ for the pass). People without the motivation to do sports can be convinced only by a low price. Recognizing the pleasure of sport as an internal reason and shortterm targets as external reasons, it must be stated that the findings correspond to those presented by P. J. Teixeira, E. V. Carraca, D. A. Markland, M. N. Silva, and R. M. Ryan (2012, pp. 78), as well as N. K. Anokye, S. Pohrel, M. Buxton, and J. Fox-Rushby (2012, pp. 277-287). Thus, there is no reason to reject research hypothesis $\mathbf{H 6}$.

Students who were (or are still) associated with sports clubs show a tendency to use paid forms of physical activity at higher prices than others. However, this rule was noticed only in single-entry fees. The contribution of people prone to pay higher prices when it comes to empirical data is $29 \%$ bigger than the theoretical value. At the same time, the decrease in the contribution of people who do not have such experiences 
as a result of determining the high price is lower only by $10 \%$. This means that sport experience has an influence on a later tendency to bear the irregular expenses for physical activity. Hence, the results of the research of Trost, Owen, Bauman, Sallis, and Brown (2002, pp. 1996-2001) are not applicable here, which implies a rejection of the $\mathbf{H 8}$ research hypothesis.

The price of complementary goods is especially important for students with low income. With a high cost for single entrance and monthly pass prices, participation in physical activity for this group will be smaller by 56\% and 50\%, respectively. So, according to what Kirby, Levin, and Inchley found (2013, pp. 954-969), not only is the price of the sport service important, but the remaining costs connected with instigating physical activity are as well. This thus provides a basis for the confirmation of the $\mathbf{H 3}$ research hypothesis.

People who take advantage of free physical activities are prone to start using paid forms only when they do not cost a lot. It is important to note that both forms of recreation can occur in a complementary manner and are not substitutionary (10\% of interviewees use both possibilities). But if the price is established earlier at a higher level, the number of people prone to use the services who have not paid so much earlier will drastically fall and will be $65 \%$ lower (single ticket) and $44 \%$ lower (pass) in relation to the theoretical value. This means that according to the suggestion of Park and Kim (2008, pp. 11-128) and Kirby, Levin, and Inchley (2013, pp. 954-969), price is an important barrier in dealing with payable physical activity among students. In the group of students already engaged in paid recreation, the assumption of Herens, van Ophem, Wegemakers, and Koelen (2015) states that the more frequently a person engages in paid physical activity, the more this person is able to pay for it. With a high price for this service, the empirical data for the use of paid forms of activity outweigh the theoretical data by about $24 \%$ of the ticket price and $34 \%$ of the pass price. On the other hand, among those who participate in non-paid forms of physical activity, the eagerness to incur large expenditures (paying at a higher price) is lower by $42 \%$ for the ticket and $61 \%$ for the monthly pass than the theoretical data. This is the basis for recognizing the truth of research hypothesis $\mathbf{H 4}$.

Students whose relatives participate in sport are able to spend more than others on physical activity. Their tendency to participate in more costly forms of physical activity exceeds the theoretical value by $20 \%$ (for a single ticket) and 36\% (for a monthly pass). This group's readiness to pay more for physical recreation corresponds with the conclusions of Gustafson and Rhodes (2006, pp. 79-97), who argue that family models influence youth participation in physical activity. Hypothesis H7, which concerns such existing relations, needs to be recognized as fulfilling the position of Candemir and Zalluhoglu (2012, pp. 29-39), which presents differing views than those mentioned below and has no use in this case.

\section{Conclusions}

Krakow is the second biggest academic center in Poland, with over 200,000 students. Among the students from Krakow who were interviewed, as many as $64 \%$ said that they at least occasionally pay to engage in physical activity. As this is a big market, it is important to have an accurate understanding of it. The thesis above meets those demands and can assess variables that influence the maximum price that students are able to pay to participate in physical activity.

On the one hand, the study shows the elements that one should take into account when creating activation programs for youth sports. On the other hand, the above-mentioned study and conclusions could be a tool that allows for the maximization of profits of sports organizations through suitable market segmentation and pricing strategy regulation. The results of the study show that commercial organizations direct their offers to students. When considering the price evolution of sports services, one should take into account the complementary goods that the market requires for participating in sport. The growth of the prevailing prices negatively influence the tendency to purchase services related to physical activities.

This paper has argued that the commercial organizations targeting students with offers related to physical activities do not have to diversify their pricing structure for the sake of gender. Students' incomes determine their consumer decisions in the area of paid forms of physical activity only when buying a monthly pass. When developing service prices, one should take into account the market of complimentary goods needed to participate in sport. The growth of prevailing prices negatively influences the tendency pay for sports services. 
Students with low income are especially sensitive to this growth. In order to acquire customers who have previously exercised for free, the commercial sector must develop a low pricing strategy. Otherwise, those students will continue to participate in their current - free - forms of activity. On the other hand, students who are already on the commercial market will accept middle and higher pricing levels. A paid offer for kinesthetic optimal recreation is a target for potential clients who exercise for pleasure, and the best place to conduct marketing actions are academies with sport profiles. These findings also have significant implications for the understanding of the creation of politics of sport popularization (also within the third sector).

The thesis is a trigger for further research on factors that shape the demand for paid forms of physical activity in Poland. Further research could usefully explore analogical research in other academic centers. The natural progression of this work is to analyze other segments of the market.

\section{REFERENCES}

Allender, S., Cowburn, G., \& Foster, C. (2006). Understanding participation in sport and physical activity among children and adults: A review of qualitative studies. Health Education Research. Theory \& Practice, 21(6), 826-835.

Anokye, N.K., Pohrel, S., Buxton, M., \& Fox-Rushby, J. (2012). The demand for sports and exercise: Results from an illustrative survey. European Journal of Health Economics, 13, 277-287.

Bandura, A. (1994). Self-efficacy. In V.S. Ramachaudran (Ed.), Encyclopedia of Human Behavior (Vol. 4; pp. 71-81). New York: Academic Press.

Belcher, R., Berrigan, D., Dodd, K.W., Emken, B. A., Cho, C., \& Spujijt-Metz, D. (2010). Physical activity in US youth: Impact of race, ethnicity, age, gender \& weight status. Medicine and science in sports and exercise, 42(12), 2211-2221.

Breuer, C., Hallmann, K., Wicker, P., \& Feier, S. (2010). Socio-economic patterns of sport demand and ageing. European Review of Aging and Physical Activity, 7(2), 61-70.

Candemir, A., \& Zalluhoglu, A.E. (2012). Factors affecting the sport related consumer expenditures. Ege Academic Review, 12, 29-39.

Cavill, N., Kahlmeier, S., \& Racioppi, F. (2006). Physical Activity and Health in Europe: Evidence for Action (p. 6). Copenhagen: WHO.

Dagkas, S., \& Stathi, A. (2007). Exploring social and environmental factors affecting adolescents' participation in physical activity. European Physical Education Review (Impact Factor: 0.5), 10/2007, 13(3), 369-384.

European Commission. (2014). Sport and Physical Activity. Special Eurobarometer [Electronic document]. Retrieved June 16, 2016, from http://ec.europa.eu/public_opinion/archives/ebs/ebs_412_en.pdf

Farrell, L., \& Shields, M.A. (2002). Investigating the economic and demographic determinants of sport participation in England. Journal of the Royal Statistical Society: Series A (Statistics in Society), 165(2), 335-348.

Gledhill, N. (2007). BTEC National Sport and Exercise Science Student Book (p. 262). Oxford: Heinemann Educational Publishers.

Główny Urząd Statystyczny. (2015). Announcements and notices [Electronic document]. Retrieved June 16, 2016, from http://stat.gov.pl/sygnalne/komunikaty-i-obwieszczenia/18,2014,kategoria.html

Gustafson, S.L., \& Rhodes, R.E. (2006). Parental correlates of physical activity in children and early adolescents. Sport Medicine, 36(1), 79-97.

Herens, M.C., van Ophem, J.A.C., Wegemakers, A.M.A.E., \& Koelen, M.A. (2015). Predictors of willingness to pay for physical activity of socially vulnerable groups in community-based programs. Springer Plus [Electronic document], 4(1), 527. Retrieved June 16, 2016, from Springer Link on the World Wide Web: http://link.springer.com/. DOI: 10.1186/s40064-015-1336-5.

Humphreys, B., \& Ruseski, J. (2011). Participation and time spent in physical activity and sport in Canada. The B.E. Journal of Economic Analysis \& Policy, 11(1), 1-38.

Hovemann, G., \& Wicker, P. (2009). Determinants of sport participation in the European Union. European Journal for Sport and Society, 6(1), 51-59.

Kilpatrick, M., Herbert, E., \& Bartholomew, J. (2005). College students' motivation for physical activity: Differentiating men's and women's motives for sport participation and exercise. Journal of American College Health, 54(2), 87-94.

Kirby, J., Levin, K.A., \& Inchley, J. (2013). Socio-environmental influences on physical activity among young people: A qualitative study. Health Education Research, 28, 954-969.

Klein, T. (2009). Determinants of sport activity and sport in the lifetime. Kolner Zeitschrift fur Soziologie und Sozialpsychologie, 61, 1-32. 
Lera-Lopez, F., \& Rapun-Garate, M. (2005). Sports participation versus consumer expenditure on sport - Different determinants and strategies in sports management. European Sport Management Quarterly, 5(2), 167-186.

Lera-Lopez, F., \& Rapun-Garete, M. (2011). Determinants of sports participation and attendance: Differences and similarities. International Journal of Sports Marketing \& Sponsorship, 12(2), 66-89.

Park, H., \& Kim, N. (2008). Predicting factors of physical activity in adolescents: A systematic review. Asian Nursing Research, 2(2), 113-128.

Prins, R.G., Ball, K., Timperio, A., Salmon, J., Oenema, A., Brug, J., \& Crawford, D. (2011). Associations between availability of facilities within three different neighborhood buffer sizes and objectively assessed physical activity in adolescents. Health Place, 17(6), 1228-34.

Strawiński, P. (2011). Economic determinants of sport participation in Poland. Rivista di Diritto ed Economia dello Sport, $6(3), 55-76$.

Stuart, J., Biddle, H., Mutrie, N., \& Gorely, T. (2015). Psychology of Physical Activity: Determinants, Well-Being and Interventions. London - New York: Routledge.

Taylor, P., \& Gratton, C. (2002). The Economics of Sport and Recreation: An Economic Analysis (pp. 50-54). New York and London: Taylor \& Francis.

Teixeira, P.J., Carraça, E.V., Markland, D.A., Silva, M.N., \& Ryan, R.M. (2012). Exercise, physical activity, and selfdetermination theory: A systematic review [Electronic version]. Journal of Behavioral Nutrition and Physical Activity, 9 , 78. Retrieved June 16, 2016, from BioMed Central on the World Wide Web: https://www.ijbnpa.biomedcentral.com. DOI: $10.1186 / 1479-5868-9-78$.

Trost, S.G., Owen, N., Bauman, A.E., Sallis, J.F., \& Brown, W. (2002). Correlates of adults' participation in physical activity: Review and update. Medicine \& Science in Sports \& Exercise, 34(12), 1996-2001.

Webber, D.J., \& Mearman, A. (2008). Student participation in sporting activity. Applied Economics, 41(9), 1183-1190.

AUTHOR'S ADDRESS: $\quad$ Szczepan Kościółek

Jagiellonian University in Kraków

Department of Management in Tourism

Prof. St. Lojasiewicza 4, 30-348 Kraków, Poland

E-mail: szczepan.kosciolek@uj.edu.pl

Received: 10 January 2017; Accepted: 24 February 2017 